Bangladesh J. Plant Taxon. 27(1): 113-127, 2020 (June)

(C) 2020 Bangladesh Association of Plant Taxonomists

\title{
GENETIC DIVERSITY OF GRAPEVINE (VITIS VINIFERA L.) CULTIVARS IN AL-MADINAH AL-MUNAWARA BASED ON MOLECULAR MARKERS AND MORPHOLOGICAL TRAITS
}

\author{
Usama K. Abdel-Hameed**1, Khawla Abdelaziz and Nahla El-Sherif ${ }^{1}$ \\ Biology Department, College of Science, Taibah University, \\ Al Madinah, Kingdom of Saudi Arabia
}

Keywords: Ampelography; Ampelometric; RAPD; ISSR; SCoT; Jaccard's coefficient and UPGMA.

\begin{abstract}
Grapevine is one of the major fruit trees in the Kingdom of Saudi Arabia. This study aims to discriminate and assess the genetic diversity in three grapevine cultivars in AlMadinah through the combination of characterization using both classical ampelographic as well as ampelometric studies with molecular markers using Randomly Amplified Polymorphic DNA (RAPD), Inter Simple Sequence Repeat (ISSR) and Start Codon Targeted Polymorphism (SCoT). For the ampelographic analysis, twelve OIV descriptors were used, and for the ampelometric analysis, the fully expanded mature leaves area were automatedly measured. The genetic distance among the three grapevines cultivars, calculated using Jaccard's coefficient, ranged from 0.7577 (between AL Nakheel and Banati) to 0.4501 (between AL Nakheel and Ahmer). The molecular analysis was based on the use of thirty-one primers; ten RAPD primers, seven ISSR primers and fourteen SCoT primers. RAPD primers generated the highest polymorphism $(67 \%)$, while the level of polymorphism with ISSR primers was $36 \%$ and with SCoT $44 \%$. All of the three markers generated similar dendrograms, and the genetic distance generated with RAPD was higher compared with SCoT and ISSR. The three markers RAPD, ISSR and SCoT were combined and amalgamated with the morphological data, and combined dendrogram was generated and discussed. AL Nakheel and Ahmer cultivars were found to be more closely related to each other than Banati which was separated in a different cluster. Both methods were effectively efficient for complete identification of grapevine and for studying the genetic diversity between closely related cultivars.
\end{abstract}

\section{Introduction}

Grapevine, Vitis vinifera L. under subfamily Ampelideae and family Vitaceae is widely cultivated for its economically valuable fruits. It is native to southwestern Asia where wild grapes still grow. Furthermore, this species is often divided into two major groups based on geographical region: the Eurasian group and the American group, and they hugely differ in their agronomic traits (Smith, 2010; Christenhusz and Byng 2016).

As a result of grapevine commercial globalization, the genetic diversity of grapevine has been decreased dramatically due to the dominant of few elite cultivars that are often preferred by consumers over the others; which lead to the spread of these cultivars worldwide and disappear of the wild or local cultivars (Myles et al., 2011). Genetic erosion or the diversity loss is one of the most serious problems at a global scale that demand considerable efforts to protect, evaluate and select the most productive samples (Musayev and Akparov, 2013). Regardless, of the high number of cultivars that exist now many of them uncommon or endangered (Portugal, 2010).

*Corresponding author, email: usama_abdelhameed@sci.asu.edu.eg

${ }^{1}$ Botany Department, Faculty of Science, Ain Shams University, Cairo, Egypt. 
Phenotyping characterization is a fundamental procedure for grapevine cultivars identifications as well as for genetic diversity analysis. There are several methods for the analysis either by a morphological description of grapevines vegetative and reproductive parts at different phenological stages (ampelography); or by the morphometry which is based on the precise measurement parameters of the plant parts (ampelometry, Rusjan, 2013).

Traditionally, the approved phenotyping study of identifying and evaluating the grapevine cultivars has been assessed by using a set of morphological characteristics which is known as ampelography (Tassie, 2010). Over the last decades, these studies have been enriched with using a different type of molecular markers to overcome the limitation of a single methodology (Sabir et al., 2009).

Ampelography studies are the first step in complete grapevine identifications. In fact, in the past decades, it was the main approved scientific methodology that has been used for grapevine description and identification (Garcia-Muñoz et al., 2011). It has been done based on a defined ampelographic descriptor of cultivars, relying on some visual traits, and these descriptors have been established a hundred years ago by pioneers ampelographers (Santiago et al., 2005).

The leaf morphological traits have a significant role in grapevine description and identification. Grapevine leaves are a very distinctive characteristic, which also, have huge diversity in comparison to other plants (Williams, 2016). There are about 50 biometric descriptors for the leaf such as size, lobes, lamina, and shape of teeth, etc. that are recognized by the intergovernmental organization OIV (2009). Moreover, these characterizations are useful to provide a base of comparison between the cultivars (Bodor et al., 2014).

The use of ampelographic description and RAPD or ISSR markers have been successful to evaluate genetic diversity in grapevine (Stavrakaki and Biniari, 2017; Zeinali et al., 2012), this has been already documented by many countries and regions (Maletić et al., 2015). In addition, several studies have found that the use of a combination of different markers will provide more comprehensive results (Marakli, 2018; Tian et al., 2018).

Moreover, according to Mao et al. (2018), study of genetic diversity with a combined markers ISSR and SCoT found that the use of both markers give a very effective, reliable and more superior results than the use of single markers. Also, other studies have found that SCoT is very correlated with neutral markers like RAPD and ISSR, and as it is gene-targeted, it might be more effective than the other markers (Gupta et al., 2018).

Biniari and Stavrakaki (2019) performed ampelographic and RAPD analysis to identify and discriminate between forty-nine Greece grapevine varieties. For the ampelographic analysis, twenty-two ampelographic characters were used. While for the RAPD molecular analysis, eight polymorphic primers were used. The study's findings revealed a high level of genetic heterogeneity as well as the degree of genetic similarity among the varieties studied. They concluded that the combination of the ampelographic analysis and molecular analysis RAPD is a very efficient method in the identification and discrimination between grapevine cultivars.

Basheer-Salimia and Mujahed (2019) studied genetic diversity and characterized thirty-six of local grapevine cultivars in Palestine by using seventeen primers of ISSR markers. A total of fiftyseven loci were scored and then the genetic distance matrix based on Jacquard's coefficient formula result in the average distance range of between 0.05 and 0.76 and the UPGMA dendrogram was conducted to show the variation between the thirty-six cultivars. Therefore, the researcher concluded that the ISSR is a very efficient tool for grapevine identification and characterizations.

Ibrahim et al. (2016) analyzed seven Egyptian grapevine varieties to assess genetic diversity using SCoT and SSR markers. For the SCoT they use 24 primers and the bands that they have 
been generated seventy-seven polymorphic bands. In order to analyze the genetic similarity between the seven varieties, they used dice coefficient and UPGMA. On one hand, SCoT analysis was successfully characterized. On other hand, they use seven SSR primers and the genetic relationship among the varieties was identified. Therefore, their results demonstrated that both Scot and SSR markers have great potential to differentiate between the grapevines varieties. SCoT technique can successfully target the generic regions across the grapevine genome, which can be used for cultivar selection and identifications.

Seyedimoradi et al. (2012) conducted a test in twenty-one grapevine cultivars of the Iran to study the genetic diversity between them. They study the morphological characters based on the IPGRI descriptors and use two molecular markers systems ISSR and directly amplified minisatellite DNA (DAMD). For the ISSR, ten primers were used and for DAMD seven primers were used. The analysis for the ISSR and DAMD markers was calculated using Nei's genetic distance and based on that dendrogram contracted by UNJ (Un-weighted Neighbor-Joining) method. They suggest that the combination of morphological and molecular markers is potential tools to studies grapevine germplasm.

Upon the lack of the study on Al-Madinah grapevine cultivars, the scope of the present study was to discriminate and assess the genetic diversity in three grapevine cultivars in Al-Madinah through the combination of characterization using both classical ampelographic as well as ampelometric studies with molecular markers using Randomly Amplified Polymorphic DNA (RAPD), Inter Simple Sequence Repeat (ISSR) and Start Codon Targetted Polymorphism (SCoT).

\section{Materials and Methods}

\section{Sampling}

Three grapevine cultivars that are traditionally grown in Al-Madinah, Saudi Arabia (Al Nakheel, Banati and Ahmer) were obtained from Bir Uthman farm $\left(24^{\circ} 29^{\prime} 43.946^{\prime \prime} \mathrm{N}\right.$, $39^{\circ} 34^{\prime} 49.608^{\prime \prime}$ E), in December 2018. The juvenile leaves (Fig. 1) were collected and kept in aluminum foil. They were appropriately labeled, sealed in a plastic container and stored at $-80^{\circ} \mathrm{C}$ in order to maintain the integrity of the tissues until DNA extraction. For the ampelography analysis, three replicates were used for each cultivar. While for the ampelometric analysis, four fully expanded mature leaves were collected from every three replicates and stored in Ziploc bags at $4^{\circ} \mathrm{C}$ until scanning.
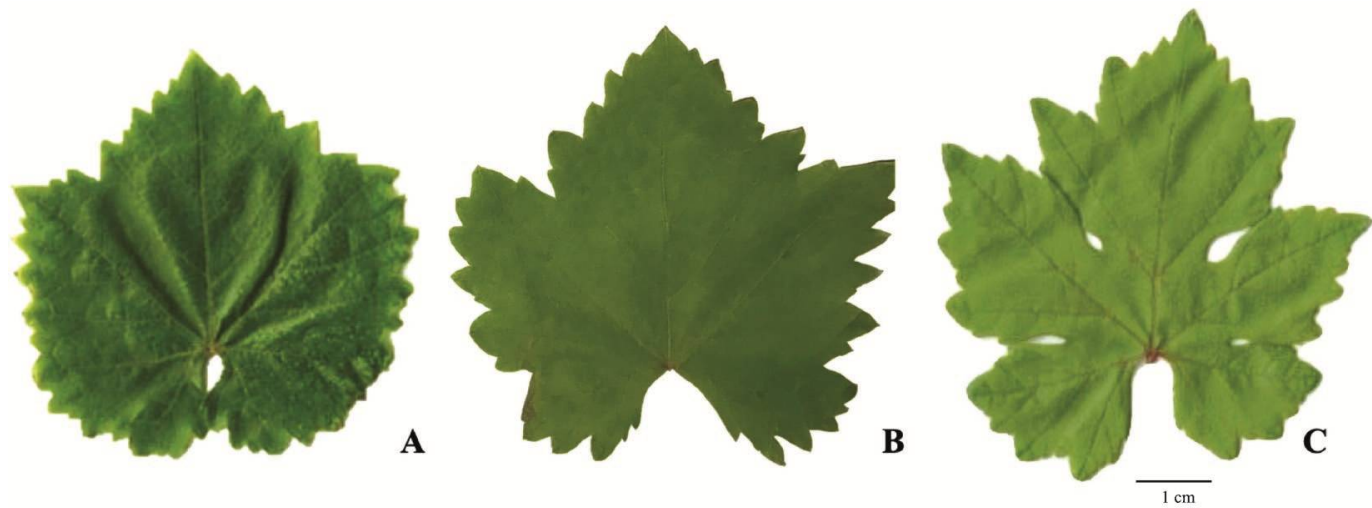

Fig.1. Samples of the measured leaves of the three grapevine cultivars from Al-Madinah, A: AL-Nakheel, B: Banati and C: Ahmer. 


\section{Morphological investigations}

The ampelography analysis was done according to the latest OIV descriptors (OIV, 2009). Twelve ampelographic characters used in this study are described in Tables 1-2. Every character was marked by an OIV code and scored by a number. Three replicates were used for each studied parameter.

Table 1. Morphological characters, their states and codes of cultivars under investigation.

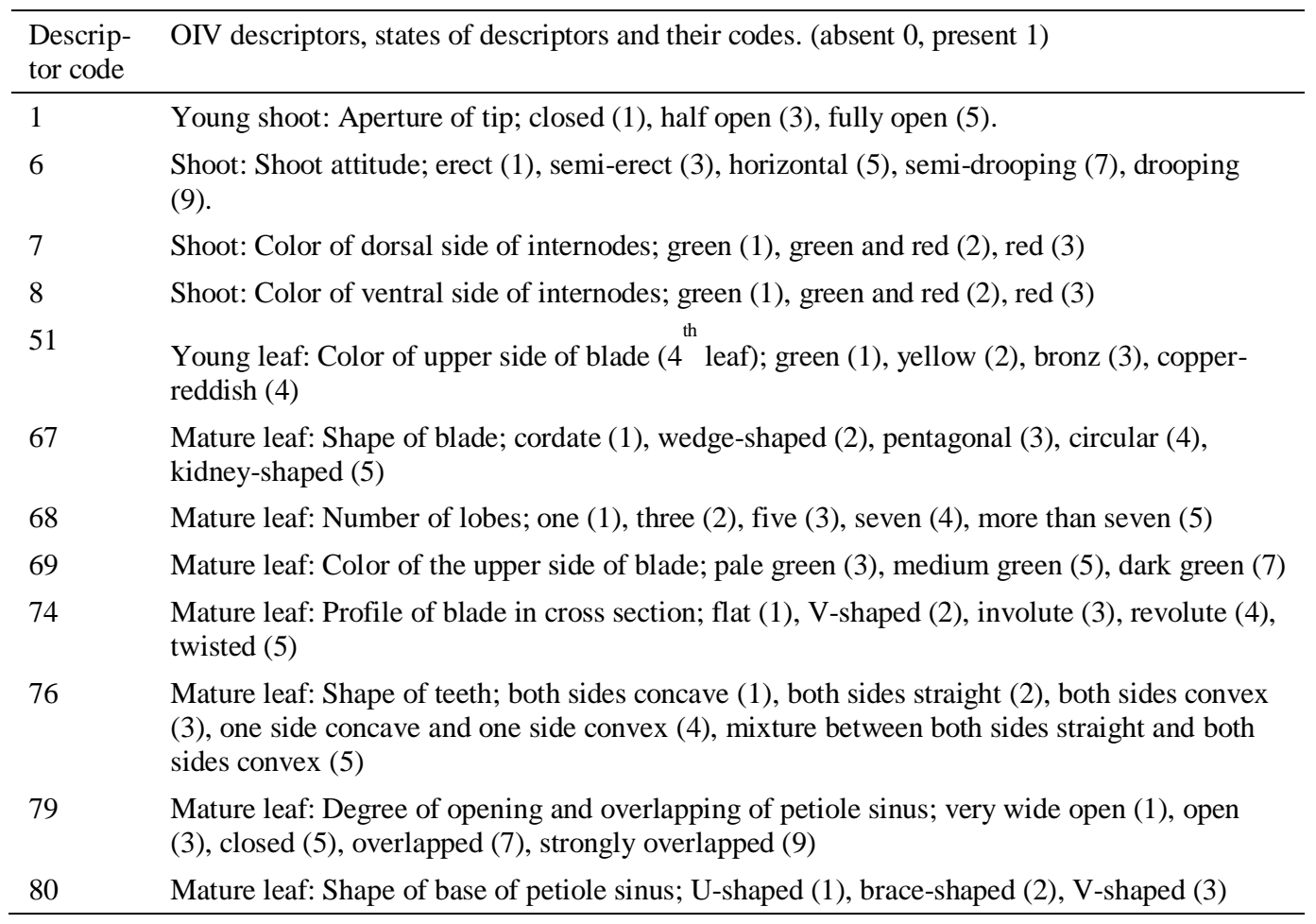

The ampelometric analysis was conducted to measure leaf area (LA), by using the fully expanded mature leaves. The leaves were digitally scanned using HP 2950 scanner with 600 dpi resolution, scans containing four leaves of the same cultivar were performed and replicated, and the leaves were arranged to prevent the overlapping. Images were saved as JPEGs with a file name indicating cultivar name and replicate number. The scanned images of twelve leaves for each cultivar were used to obtain the automated measurements using Digimizer (Version 5.4- image analysis software).

\section{Molecular investigations}

DNA was extracted from juvenile grapevine leaves using GenCatch Plant Genomic DNA Purification Kit (Epoch Life Science), according to kit protocol. To determine the integrity of the DNA, $5 \mu \mathrm{l}$ of DNA with loading dye (Thermo Fisher Scientific) for each sample was electrophoresed on a $1.2 \%$ agarose gel. The purity and concentration were measured by using the NanoDrop 2000/2000 Spectrophotometer (Thermo Fisher Scientific). DNA purity was determined by calculating the absorbance at 260 and $280 \mathrm{~nm}$. A part of the DNA stock was diluted with the 
appropriate amount of sterilized deionized water to yield a concentration of $10 \mathrm{ng} / \mu \mathrm{l}$ and then stored at $-20^{\circ} \mathrm{C}$.

The PCR reaction was carried out in the Applied Biosystems Veriti Thermal Cycler. The program was based on DreamTaq Green PCR Master Mix (2X) (Thermo Fisher Scientific) instructions with some modifications.

For RAPD, ISSR and ScoT PCR analysis, reactions were carried out in $25 \mu$ l volume containing $3 \mu \mathrm{l}$ of ( $30 \mathrm{ng}$ ) template DNA, $1 \mu \mathrm{M}$ primer, $8.5 \mu \mathrm{l}$ of nuclease-free water and 12.5 of DreamTaq Green PCR Master Mix (2X) (Thermo Fisher Scientific) which contained (DreamTaq DNA Polymerase, 2X DreamTaq Green buffer, dNTPs, and $4 \mathrm{mM} \mathrm{MgCl}_{2}$ ), and $8.5 \mu 1$ of nucleasefree water.

For RAPD, the thermal cycler was programmed for a 'hot start' for 3 minutes at $95^{\circ} \mathrm{C}$ followed by 1 -minute denaturation at $94^{\circ} \mathrm{C}, 3$ minutes annealing at $33^{\circ} \mathrm{C}$ and 2 -minute extension at $72^{\circ} \mathrm{C}$. These steps were repeated for 34 cycles followed by a 10-minute final extension step at $72^{\circ} \mathrm{C}$. Initial screening was done using the 10 RAPD primers (Operon Technologies) with the DNA from the three grapevine cultivars.

Table 2. Ampelographic description of three grapevine cultivars from Al-Madinah using twelve OIV descriptors of shoot and leaves (the data are the mean of the three replicates).

\begin{tabular}{llccc}
\hline \multirow{2}{*}{ OIV descriptors } & \multicolumn{3}{c}{ Cultivar } & \\
\cline { 3 - 5 } & & AL Nakheel & Banati & Ahmer \\
\hline 1 & Young shoot: Aperture of tip & 3 & 1 & 1 \\
6 & Shoot: Shoot attitude & 2 & 3 & 3 \\
7 & Shoot: Color of dorsal side of internodes & 2 & 2 & 2 \\
8 & Shoot: Color of ventral side of internodes & 1 & 2 & 2 \\
51 & Young leaf: Color of upper side of blade (4th leaf) & 4 & 1 & 1 \\
67 & Mature leaf: Shape of blade & 2 & 4 & 4 \\
68 & Mature leaf: Number of lobes & 7 & 3 & 3 \\
69 & Mature leaf: Color of the upper side of blade & 1 & 5 & 5 \\
74 & Mature leaf: Profile of blade in cross section & 3 & 3 & 1 \\
76 & Mature leaf: Shape of teeth & 7 & 3 & 3 \\
79 & Mature leaf: Degree of opening and overlapping & 1 & 3 & 1 \\
80 & Mature leaf: Shape of base of petiole sinus & & 3 \\
\hline
\end{tabular}

For ISSR analysis, thermocycler program for PCR was set to a 'hot start' for 3:15 minutes at $94^{\circ} \mathrm{C}$ followed by 30 seconds denaturation at $94^{\circ} \mathrm{C}, 45$ seconds annealing at $43-55^{\circ} \mathrm{C}, 2$ minutes extension at $72^{\circ} \mathrm{C}$, the program was repeated for 30 cycles at $94^{\circ} \mathrm{C}$ and 7 minutes final extension at $72^{\circ} \mathrm{C}$. To choose appropriate ISSR primers from fourteen available primer (Table 3), an initial screening was performed and only seven polymorphic ISSR primers out of fourteen were selected. Those are: ISSR-5, ISSR-7, ISSR-12, ISSR-13, ISSR-14, ISSR-19 and ISSR-20.

For ScoT, PCR was programmed as follows: 'hot start' for 3 minutes at $94^{\circ} \mathrm{C}$ followed by 1 minute denaturation at $94^{\circ} \mathrm{C}, 1$-minute annealing at $50-59^{\circ} \mathrm{C}$ (the temperature is determined according to GC\% content of the primer), 2 minutes extension at $72^{\circ} \mathrm{C}$. The program was repeated for 35 cycles followed by a 5-minute final extension step at PCR was programmed as follows: 'hot start' for 3 minutes at $94^{\circ} \mathrm{C}$ followed by 1 minute denaturation at $94^{\circ} \mathrm{C}, 1$ minute annealing at 50$59^{\circ} \mathrm{C}$ and 2 minute extension at $72^{\circ} \mathrm{C}$. Fourteen ScoT primers were used for the analysis. 
All amplified products using the 3 molecular markers were loaded in 1.2\% agarose gel and electrophoresed against a $1 \mathrm{~Kb}$ Plus DNA ladder (Thermo Fisher Scientific). The gels were documented using a UV light on the omniDOC gel documentation system (Cleaver Scientific).

\section{Phenetic analysis}

Ampelographic definitions were used according to the international descriptors (OIV, 2009). Phenotypic similarity matrix, based on 12 OIV descriptors with 17 character states (Table 1) was constructed.

Gel images from 31 primers of RAPD, ISSR and SCoT markers were manually scored into a binary matrix, the presence of a band was scored as " 1 ", and absence of a band as "0". The intensity of polymorphic bands was not taken into account during the scoring. Each band was considered as a locus.

The two sets of data (morphological and molecular) were amalgamated and used for computations by aid of NTSYS (Numerical Taxonomy and Multivariate Analysis System) Version 2.2 software (Rohlf, 2000). Genetic distance among the studied three grape cultivars was estimated using SIMQUAL (Similarity for qualitative data) techniques. After that, a dendrogram was constructed by SAHN (sequential, agglomerative hierarchical and nested clustering) using UPGMA (Unweighted Pair Group Method with Arithmetic Average) method algorithm due to (Sneath and Sokal, 1973).

\section{Results and Discussion}

\section{Ampelography and ampelometry}

The three grapevines cultivars AL Nakheel, Banati and Ahmer were analyzed using twelve OIV descriptors (Table 2). Seven of those characters correspond to a mature leaf and the remainder five to the shoot.

The different cultivars were distinguished based on these morphological characters. Moreover, the results of the expression of features were defined by OIV descriptors indicating that eight descriptors were scored identical in all cultivars, which includes the closed young shoot tip (OIV 001), the semi-erect shoot attitude (OIV 006), the green and red color of dorsal side of internodes (OIV 007), green and red color of ventral side of internodes (OIV 008), green color of upper side of young leaf blade (4th leaf) (OIV 051), the circular mature leaf blade (OIV 067), the flat mature leaf profile of blade in cross-section (OIV 074) and the convex sides of the teeth on the leaf margin (OIV 076). While the others four descriptors were different, which were related mainly to the mature leaves: number of lobes is three $v s$. five (OIV 068), color of the upper side of mature leaf is dark green (OIV 069), and degree of opening and overlapping of mature leaf open, closed and overlapped (OIV 079), while the shape of mature leaf base of petiole sinus was Ushaped vs. V-shaped (OIV 080). Data obtained from the ampelometric measurements of the fully expanded mature leaves area of the three grapevine cultivars are given in Table 3 and Fig. 1.

\section{Molecular markers RAPD, ISSR, and SCoT}

The results indicated that the used ten RAPD primers successfully amplified the template DNAs of the three grapevine cultivars (Table 4, Fig. 2A \& B). Seven ISSR primers were selected out of fourteen, and they generated total forty-four amplified bands (Table 5, Fig. 3 A \& B). In addition, fourteen informative SCoT primers were used to assess the genetic diversity of the three grapevine cultivars (Table 6, Fig. 4A, B \& C).

Genetic diversity data of the three grapevines cultivars are summarized in Table 7. The data were obtained by the combination of three molecular markers RAPD, ISSR, and SCoT, which 
were in total thirty-one primers and the total bands were 205. Among them, 81 bands were polymorphic.

Table 3. Mean values of leaf area measurements of the three grapevine cultivars from Al-Madinah, three replicate four-leaf for each cultivar.

\begin{tabular}{lcc}
\hline Cultivars & Mean $\left(\mathrm{cm}^{2}\right)$ & Standard deviation \pm \\
\hline AL Nakheel & 31 & 1.7 \\
Banati & 48 & 3.0 \\
Ahmer & 40 & 2.7 \\
\hline
\end{tabular}

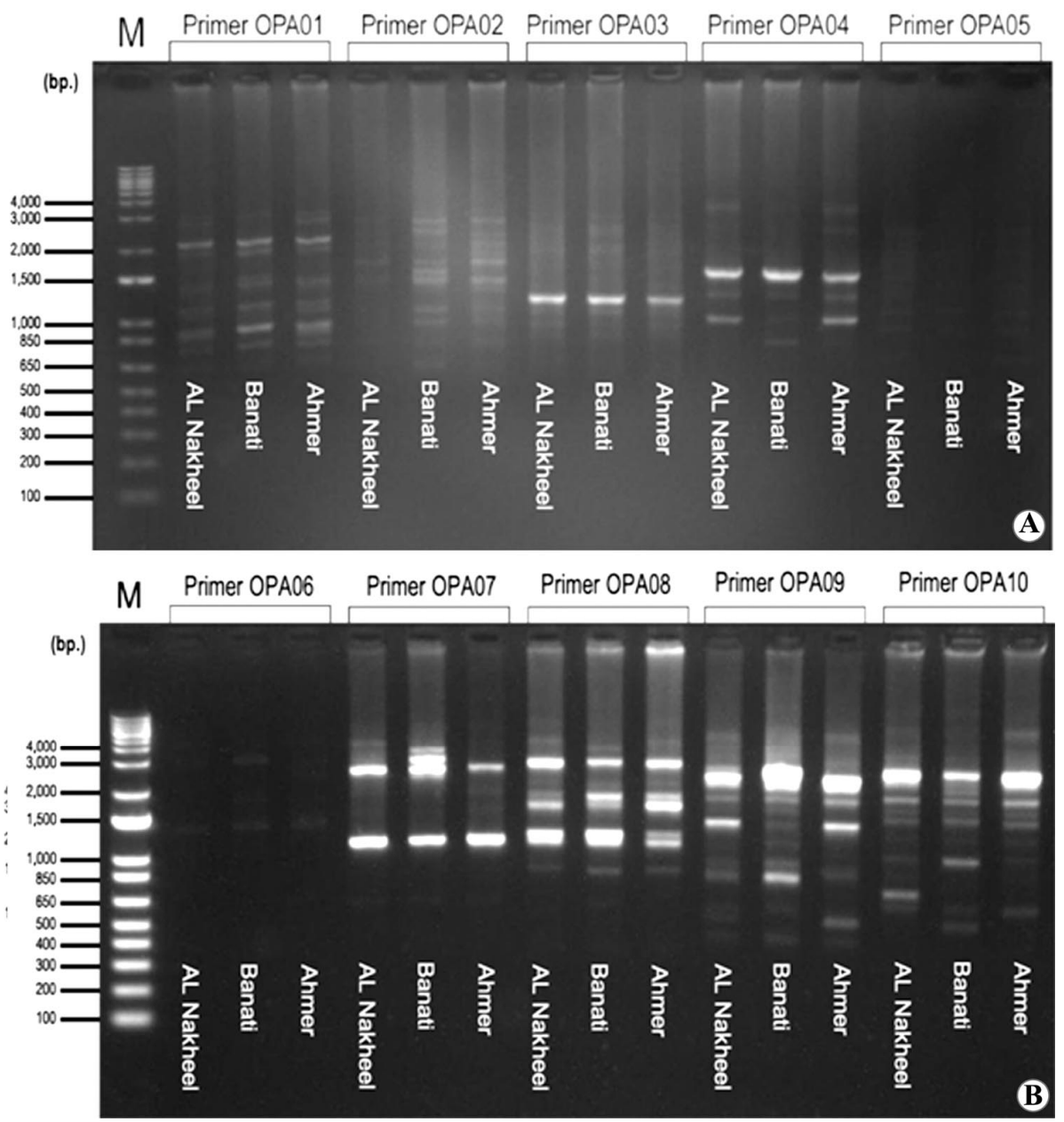

Fig. 2. Gel electrophoresis (1.2\%) profile of the amplified DNA fragments of the three grapevine cultivars that generated with RAPD primers. A. OPA-01, OPA-02, OPA-03, OPA-04 and OPA-05. B. OPA-06, OPA-07, OPA-08, OPA-09 and OPA-10. M: 1 Kb DNA Ladder (Thermo Fisher Scientific). 

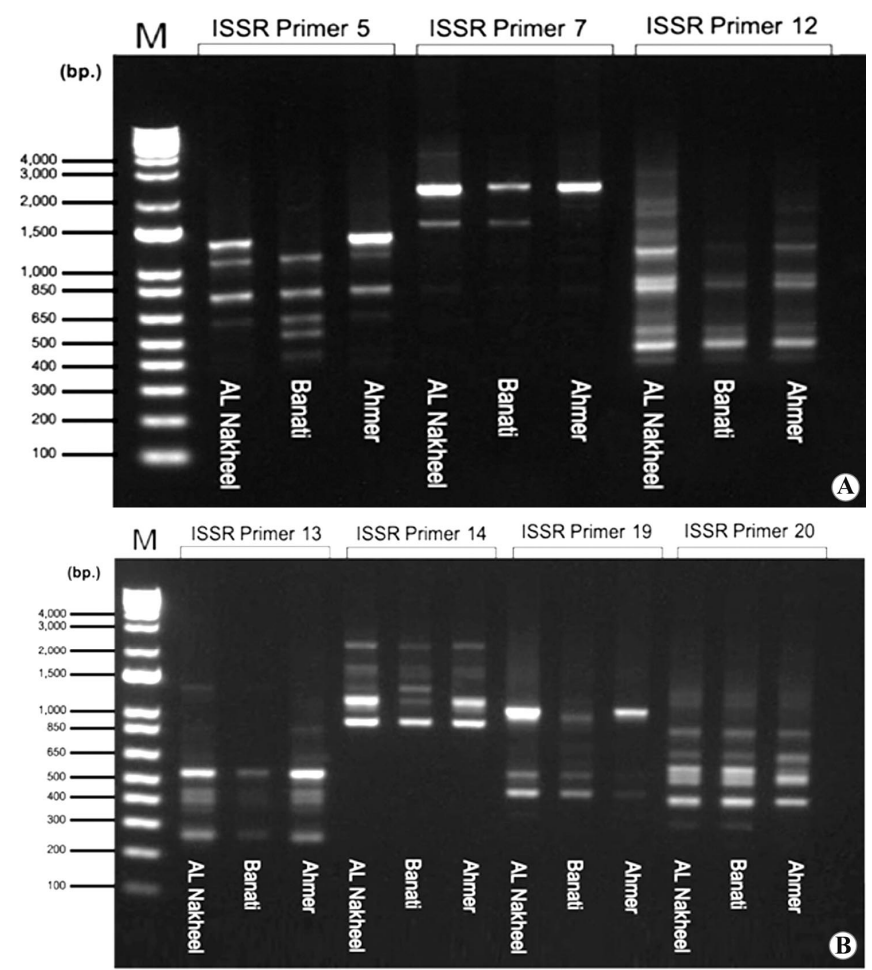

Fig. 3. Gel electrophoresis $(1.2 \%)$ profile of the amplified DNA fragments of the three grapevine cultivars that generated with ISSR primers A. ISSR- 5, ISSR- 7 and ISSR- 12. B. ISSR- 13, ISSR- 14, ISSR- 19 and ISSR- 20 M: $1 \mathrm{~Kb}$ DNA Ladder (Thermo Fisher Scientific).

Table 4. RAPD analysis of the bands obtained from gel electrophoresis profile of the amplified DNA from the three grapevine cultivars that generated with the ten RAPD primers, SD: standard deviation.

\begin{tabular}{lcccccc}
\hline $\begin{array}{l}\text { Primer } \\
\text { code }\end{array}$ & $\begin{array}{c}\text { Total no. of } \\
\text { bands (bp) }\end{array}$ & $\begin{array}{c}\text { Monomorphic } \\
\text { bands (bp) }\end{array}$ & $\begin{array}{c}\text { Unique bands } \\
(\mathrm{bp})\end{array}$ & $\begin{array}{c}\text { Polymorphic } \\
\text { bands (bp) }\end{array}$ & $\begin{array}{c}\text { Polymorphism } \\
(\%)\end{array}$ & $\begin{array}{c}\text { Size range } \\
(\mathrm{bp})\end{array}$ \\
\hline OPA-01 & 7 & 1 & 0 & 6 & 86 & $650-3,000$ \\
OPA-02 & 8 & 1 & 4 & 7 & 88 & $650-4,000$ \\
OPA-03 & 4 & 2 & 0 & 2 & 50 & $1000-3,000$ \\
OPA-04 & 6 & 2 & 2 & 4 & 67 & $850-3,000$ \\
OPA-05 & 4 & 1 & 1 & 3 & 75 & $400-4,000$ \\
OPA-06 & 2 & 1 & 1 & 1 & 50 & $1500-3,000$ \\
OPA-07 & 5 & 2 & 2 & 3 & 60 & $1,200-4,000$ \\
OPA-08 & 9 & 7 & 1 & 2 & 22 & $850-5,000$ \\
OPA-09 & 10 & 4 & 2 & 6 & 60 & $400-2,800$ \\
OPA-10 & 9 & 4 & 2 & 5 & 56 & $500-5,000$ \\
Total & 69 & 27 & 15 & 42 & - & - \\
Mean & 6.9 & 2.7 & 1.5 & 4.2 & 67 & - \\
SD & 2.6 & 2.0 & 1.2 & 2.0 & 19.4 & - \\
\hline
\end{tabular}



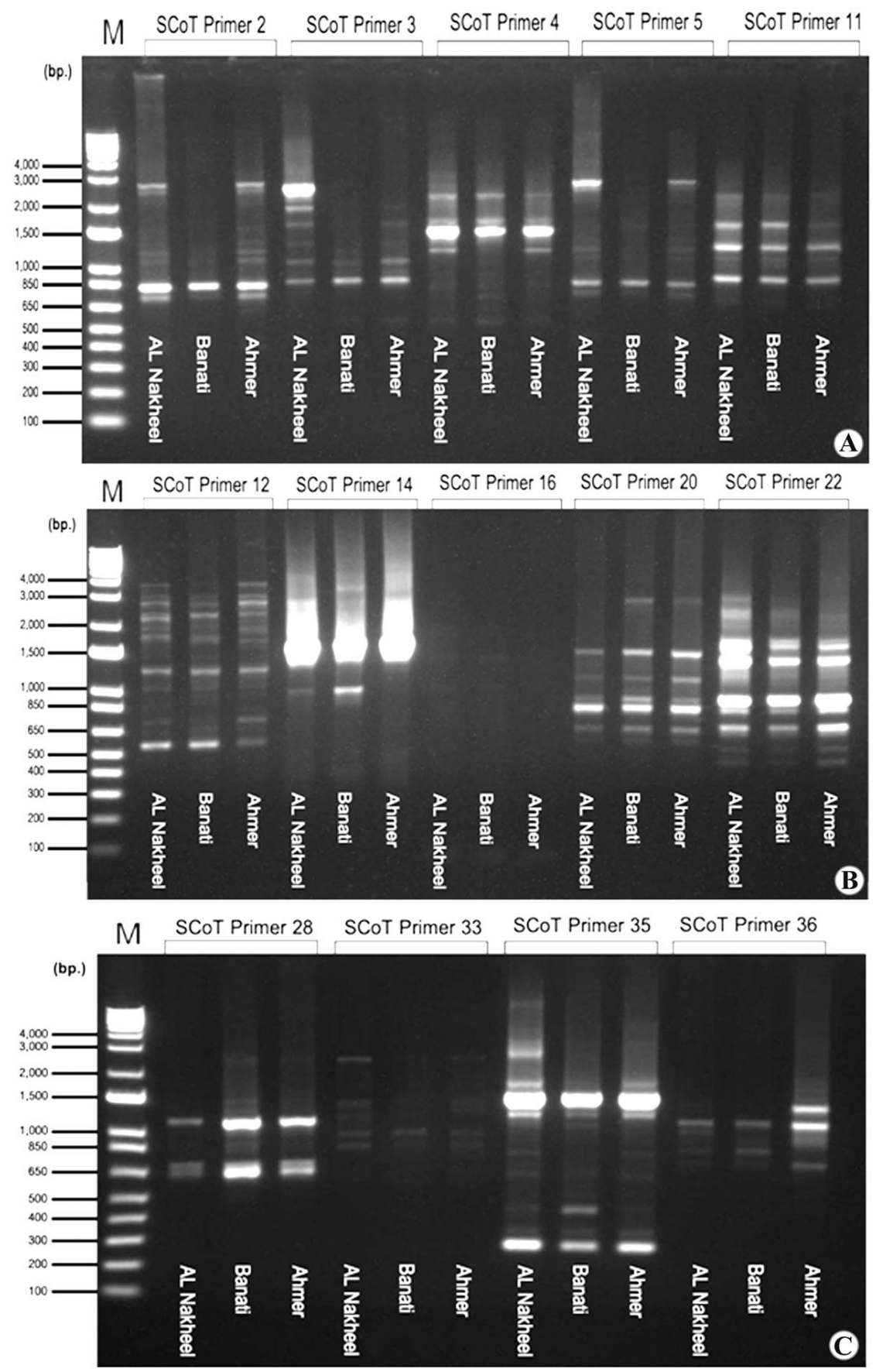

Fig. 4. Gel electrophoresis (1.2\%) profile of the amplified DNA fragments of the three grapevine cultivars that generated with SCoT primers. A. SCoT -2, SCoT-3, SCoT-4, SCoT-5 and SCoT-11. B. SCoT-12, SCoT-14, SCoT-16, SCoT-20 and SCoT-22. C. SCoT-28, SCoT-33, SCoT-35 and SCoT-36. M: 1 Kb DNA Ladder (Thermo Fisher Scientific). 
Table 5. ISSR analysis of the bands obtained from the gel electrophoresis profile of the amplified DNA of the three grapevine cultivars that generated with the seven ISSR primers, SD: standard deviation.

\begin{tabular}{lcccccc}
\hline $\begin{array}{l}\text { Primer } \\
\text { code }\end{array}$ & $\begin{array}{c}\text { Total no. of } \\
\text { bands (bp) }\end{array}$ & $\begin{array}{c}\text { Monomorphic } \\
\text { bands (bp) }\end{array}$ & $\begin{array}{c}\text { Unique bands } \\
(\mathrm{bp})\end{array}$ & $\begin{array}{c}\text { Polymorphic } \\
\text { bands (bp) }\end{array}$ & $\begin{array}{c}\text { Polymorphism } \\
(\%)\end{array}$ & $\begin{array}{c}\text { Size range } \\
(\mathrm{bp})\end{array}$ \\
\hline ISSR- 5 & 6 & 3 & 2 & 3 & 50 & $400-1,500$ \\
ISSR- 7 & 4 & 2 & 1 & 2 & 50 & $850-4,000$ \\
ISSR- 12 & 10 & 6 & 2 & 4 & 40 & $400-2,000$ \\
ISSR- 13 & 6 & 4 & 2 & 2 & 33 & $250-1,500$ \\
ISSR- 14 & 5 & 4 & 0 & 1 & 20 & $850-2,000$ \\
ISSR- 19 & 4 & 2 & 1 & 2 & 50 & $450-1,000$ \\
ISSR- 20 & 9 & 8 & 0 & 1 & 11 & $300-1,300$ \\
Total & 44 & 29 & 8 & 15 & - & - \\
Mean & 6.3 & 4.1 & 1.1 & 2.1 & 36 & - \\
SD & 2.4 & 2.2 & 0.9 & 1.1 & 15.8 & - \\
\hline
\end{tabular}

Table 6. SCoT analysis of the bands obtained from gel electrophoresis profile of the amplified DNA of the three grapevine cultivars that generated with the fourteen SCoT primers, SD: standard deviation.

\begin{tabular}{lcccccc}
\hline $\begin{array}{l}\text { Primer } \\
\text { code }\end{array}$ & $\begin{array}{c}\text { Total no. of } \\
\text { bands }(\mathrm{bp})\end{array}$ & $\begin{array}{c}\text { Monomorphic } \\
\text { bands (bp) }\end{array}$ & $\begin{array}{c}\text { Unique bands } \\
(\mathrm{bp})\end{array}$ & $\begin{array}{c}\text { Polymorphic } \\
\text { bands }(\mathrm{bp})\end{array}$ & $\begin{array}{c}\text { Polymorphism } \\
(\%)\end{array}$ & $\begin{array}{c}\text { Size range } \\
(\mathrm{bp})\end{array}$ \\
\hline SCoT-2 & 8 & 6 & 1 & 2 & 25 & $400-2,800$ \\
SCoT-3 & 6 & 4 & 3 & 2 & 33 & $650-2500$ \\
SCoT-4 & 7 & 3 & 2 & 4 & 57 & $500-2,500$ \\
SCoT-5 & 5 & 2 & 0 & 3 & 60 & $750-3,000$ \\
SCoT-11 & 5 & 5 & 0 & 0 & 0 & $850-2,500$ \\
SCoT-12 & 12 & 9 & 1 & 3 & 25 & $600-4,000$ \\
SCoT-14 & 3 & 1 & 1 & 2 & 67 & $1,000-3,900$ \\
SCoT-16 & 2 & 0 & 0 & 2 & 100 & $1,000-1,500$ \\
SCoT-20 & 7 & 6 & 0 & 1 & 14 & $600-3,000$ \\
SCoT-22 & 12 & 3 & 3 & 9 & 75 & $400-3,000$ \\
SCoT-28 & 6 & 3 & 2 & 3 & 50 & $650-2,500$ \\
SCoT-33 & 4 & 4 & 0 & 0 & 0 & $2,500-850$ \\
SCoT-35 & 10 & 5 & 2 & 5 & 50 & $290-2,500$ \\
SCoT-36 & 5 & 2 & 2 & 3 & 60 & $650-1,300$ \\
Total & 92 & 53 & 17 & 39 & - & - \\
Mean & 6.6 & 3.8 & 1.2 & 2.9 & 44 & - \\
SD & 3.1 & 2.3 & 1.1 & 2.3 & 29.1 & - \\
\hline
\end{tabular}




\section{Phenogram}

The UPGMA phenogram (Fig. 5) produced upon the amalgamation of molecular analyses with ampelographic and ampelometric studies shows clustering of the studied cultivars into two major lineages, at a reference line of about 0.63 , one includes AL Nakheel and Ahmer as sister cultivars at similarity value 0.70 , while the other has Banati cultivar.

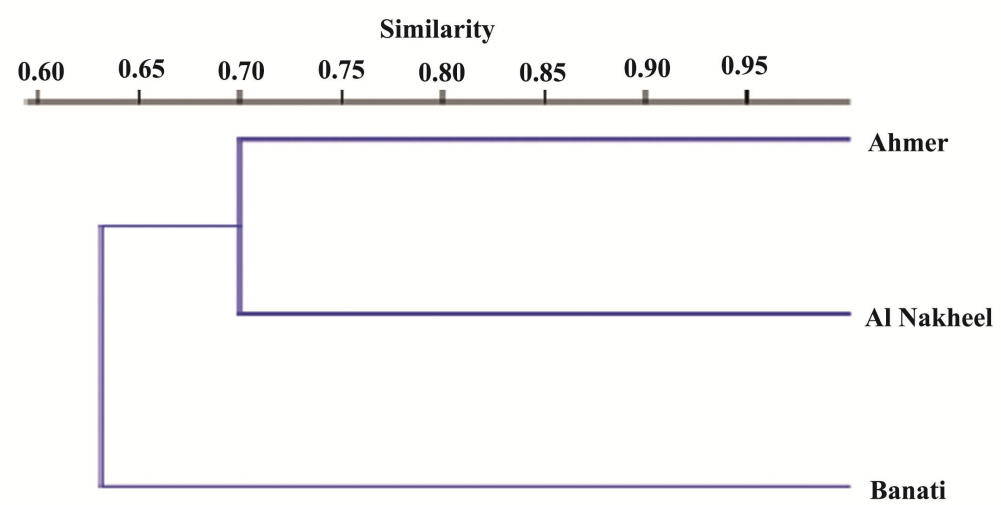

Fig. 5. Phenogram illustrating the genetic relationship among the three grapevine cultivars based on morphological characters (ampelomorphic and ampelometric) and molecular markers (RAPD, ISSR and SCoT) constructed by UPGMA with Jaccard's coefficient.

\section{Morphological analysis}

Most of the grapevine growers in Al-Madinah identify the cultivars based on a few visible morphological traits. In the present study, twelve OIV descriptors were evaluated and the reason behind choosing this set of descriptors was to identify and study the genetic diversity between the three grapevine cultivars. Therefore, two main distinctive characters of the grapevine were selected (shoot and mature leaves). Also, the quantitatively measurable traits such as mature leaf number of lobes and leaf area were studied.

Therefore, the most important characters that were able to discriminate between the cultivars were: OIV 068, OIV 069, OIV 079 and OIV 080 (mature leaf; the number of lobes, the colour of the upper side of the blade, the degree of opening and shape of the base of petiole sinus), while the remaining eight descriptors revealed no significant difference between the cultivars.

In a similar study, (Dilli et al., 2014) studied fourteen grape cultivars using fifty-seven ampelographic characteristics of shoot and leaf, inflorescence, berries and seeds, and their results agree with the results generated in the present study where the differences were most relevant to the mature leaves. This finding was also reported by Santiago et al. (2007); Ates et al. (2011), where they found that the mature leaf was very informative in discriminating grapevine genotypes, and also it was more stable and objective than other characters. Also, according to Bodor et al., (2014), description of the leaf has a great importance since it is different from the other morphological characters where the characterization is not limited by a certain time through the year.

The ampelometric results were also able to show the difference between the three cultivars where AL Nakheel was the smallest and Ahmer in the middle then Banati was the largest. This finding was also reported by many studies (Santiago et al., 2005; Soldavini et al., 2009) where they also measured the ampelometric traits of grapevine cultivars using digital imaging which was found to be a powerful tool, accurate and objective. Alba et al., (2014) stated that in recent years 
the ampelometric traits have been very useful in grapevine since they differentiate between the genotypes based on metric scales of the characteristics of a mature leaf, which therefore can be compared with other studies.

Overall, the present investigations support the observations of Sabir et al., (2009) who suggested that classical morphological studies such as ampelographic and ampelometric ones are considered important and useful methods for genetic diversity study and cultivars identification, but still not dependable and therefore need to be used in combination with molecular studies.

\section{Molecular analysis}

In the present study, the level of genetic polymorphism between three traditionally grown grapevine cultivars in Al-Madinah was estimated using a combination of three dominant genetic molecular markers: RAPD, ISSR and SCoT. The collected data were used to compare the similarity values obtained with these different marker techniques. The polymorphic bands generated by these markers using thirty-one primers showed variance between the three grapevine cultivars. As reported by This et al. (2006) the primers used in the study were found to differ in the pattern of efficiency and reproducibility. Besides, they reported that primer selection is very significant in cultivar identifications. In this study, the RAPD primer OPA-02 revealed a high capacity for grapevine cultivar discrimination. The high number of polymorphic bands with the average percentage $67 \%$ was comparable to the results of Castro et al. (2016). The average polymorphism among local cultivars was found to be $65.49 \%$, using twenty-five primers. The size of the amplified bands obtained in this study ranged from 400 to 5,000 bp, which was a wider interval than that obtained from the results of Basheer-Salimia and Mujahed (2019), which were 150 to 1,400 bp for different grapevine cultivars in Palestine. Several similar studies reported the effectiveness of ISSR for grapevine cultivar discrimination (Zeinali et al., 2012; Basheer-Salimia and Mujahed (2019). In this study, the total number of polymorphic bands generated by ISSR using the seven primers was 15 and the average polymorphism was $36 \%$. The amplified band size ranged from 250 to $4,000 \mathrm{bp}$.

On the other hand, the 14 SCoT primers amplified 39 polymorphic bands where the average polymorphism was $44 \%$ and the average number of bands per primer was 2.9. The bands ranged from 290 to 4,000 bp. In a similar study, Ibrahim et al. (2016) used 24 SCoT primers to evaluate seven grapevine varieties which generated 279 polymorphic bands with an average polymorphism of $77 \%$. The product sizes ranged between 140 and 2,150 bp.

Therefore, when comparing the results of present study with the previous studies, it must be pointed out that the average polymorphism and the average number of bands per primer in this study were lower than the previously determined polymorphism levels, although, the molecular weight of the bands in this study were higher than the mentioned studies. A comparison of the level of polymorphism of RAPD, ISSR and SCoT markers was presented in Table 7; the higher polymorphism indicates a higher genetic diversity. Additionally, the discriminating power and the efficiency of a marker technique depends on polymorphism value. The average number of polymorphic bands of the used markers were largely differed. RAPD showed the highest average polymorphism (67\%) and this result is agreed with Kallamadi et al. (2015), where the RAPD level of polymorphism was (54\%) which was higher than that obtained with ISSR (38\%) and SCoT (21\%). The average polymorphism obtained with ISSR was 36\% and with SCoT $44 \%$, the higher level of polymorphism detected by RAPD markers than with SCoT and ISSR highlights the discriminating capacity of the former. In addition, the average size of RAPD bands was larger than that of ISSR as well as SCoT and the average band size of these two were nearly the same. The possible explanation for these differences in polymorphism level, as already reported in the literature, is that each marker technique targets different regions of the genome hence this results 
in a different pattern of discrimination in genetic diversity. Kallamadi et al. (2015) explained that SCoT low polymorphism might be due to the very low genetic difference in the conserved regions of the genome.

Table 7. Comparison and total data generated from the three molecular markers RAPD, ISSR, and SCoT markers.

\begin{tabular}{lccc}
\hline Markers & RAPD & ISSR & SCoT \\
\hline Mean of the total number of bands & 6.9 & 6.3 & 6.6 \\
\hline Mean of the total number of polymorphic bands & 4.2 & 2.1 & 2.9 \\
\hline Percentage of polymorphism $(\%)$ & 67 & 36 & 44 \\
\hline
\end{tabular}

Phenetic analysis

The amalgamation of morphological and molecular traits gave a robust pheneogram that clarified the close relationship between AL Nakheel and Ahmer rather than Banati. The combination of the two data sets, morphological and molecular, was efficient and provided more information, clear and accurate way to study the genetic diversity among the grapevine cultivars, this is in accord with Seyedimoradi et al. (2012), as well as in other plants by Sesli and Yegenoglu (2017).

It is concluded that, the present study highlights the necessity and importance of morphological analysis (ampelographic and ampelometric) as the first step for characterization, in addition to the molecular analyses (RAPD, ISSR, and SCoT), in order to carry a complete and accurate characterization of the three grapevine cultivars traditionally grown in Al-Madinah AlMunawarah (Al Nakheel, Banati and Ahmer). Morphological characters, alone, might be insufficient to differentiate the closely related cultivars and might be influenced by environmental factors, thus the need for molecular markers is justified. Furthermore, the results demonstrate the potential use of RAPD, ISSR and SCoT marker systems, which may reflect grapevine evolution and reveal its specific characteristics. The selected primer sets of RAPD revealed the highest polymorphism, whereas SCoT had an intermediate value and the ISSR were the lowest. According to the combination of the three markers and morphological characteristics, genetic distance value was minimum between Al Nakheel and Ahmer. Therefore, this valuable information on the relationships among the three cultivars can be considered as a first step toward the identification and characterization of Al-Madinah grapevine. These findings could be useful for grapevine germplasm conservations and breeding programs.

\section{References}

Alba, V., Bergamini, C., Cardone, M.F., Gasparro, M., Perniola, R., Genghi, R. and Antonacci, D. 2014. Morphological variability in leaves and molecular characterization of novel table grape candidate cultivars (Vitis vinifera L.). Mol. Biotechnol. 56:557-570.

Ates, F., Coban, H., Kara, Z. and Sabir, A. 2011. Ampelographic characterization of some grape cultivars (Vitis vinifera L.) grown in south-western region of Turkey. Bulg. J. Agric. Sci. 17:314-324.

Basheer-Salimia, R. and Mujahed, A. 2019. Genetic diversity of grapevine ( Vitis vinifera L.) as revealed by ISSR markers . J. Plant Biotechnol. 46:1-8.

Biniari, K. and Stavrakaki, M. 2019. Genetic study of native grapevine varieties of northern, western and central Greece with the use of ampelographic and molecular methods. Not. Bot. Horti Agrobot. ClujNapoca 47:46-53.

Bodor, P., Baranyai, L., Parrag, V. and Bisztray, G. 2014. Effect of row orientation and elevation on leaf morphology of grapevine ( Vitis vinifera L.) c.v. Furmint . Prog. Agric. Eng. Sci. 10:53-69. 
Castro, I., Pinto-Carnide, O., Marcide, J.M.O., Ferreira, V. and Clemente, J.P.M. 2016. A comparative analysis of genetic diversity in portuguese grape germplasm from ampelographic collections fit for quality wine production. Spanish J. Agric. Res. 14, 13.

Christenhusz, M.J.M and Byng J.W. 2016. number known plants species world its Annu. increase. Phytotaxa 261, 201.

Dİlli, Y., Ünal, A., Kesgİn, M., İnan, M.S. and Söylemezoğlu, G. 2014. Comparison of Ampelographic Characteristics of Some Important Grape Varieties are Grown in The Aegean Region, Rootstock and Clones. Türk Tarım ve Doğa Bilim. Derg. 1: 1546-1553.

Garcia-Muñoz, S., Muñoz-Organero, G., Andrés, M.T. De and Cabello, F. 2011. Ampelography - An old technique with future uses: The case of minor varieties of vitis vinifera L. from the balearic islands. J. Int. des Sci. la Vigne du Vin 45:125-137.

Gupta, D.D., Hui, P.K. and Tag, H. 2018. Genotypic variation in Acmella paniculata across different phytogeographical ranges of Northeast India inferred through ISSR \& SCoT based markers. J. Appl. Res. Med. Aromat. Plants 11:3-11.

Ibrahim, S.D., Adawy, S.S., Atia, M.A.M., Alsamman, A.M. and Mokhtar, M.M. 2016. Genetic diversity, variety identification and gene detection in some Egyptian grape varieties by SSR and SCoT markers. Plant Omics 9:311-318.

Kallamadi, P.R., Nadigatla, V.P.R.G.R. and Mulpuri, S. 2015. Molecular diversity in castor (Ricinus communis L.). Ind. Crops Prod. 66:271-281.

Maletić, E., Pejić, I., Karoglan K,J., Zdunić, G., Preiner, D., Šimon, S., Andabaka, Ž,M., Bubola, M., Marković, Z., Stupić, D. and Mucalo, A. 2015. Ampelographic and genetic characterization of Croatian grapevine varieties. Vitis - J. Grapevine Res. 54:93-98.

Mao, R., Xia, P., Liu, J., Li, X., Han, R., Liu, F., Zhao, H. and Liang, Z. 2018. Genetic diversity and population structure assessment of Chinese Senna obtusifolia L. by molecular markers and morphological traits of seed. Acta Physiol. Plant. 40. https://doi.org/10.1007/s11738-017-2586-3

Marakli, S. 2018. A Brief Review of Molecular Markers to Analyse Medically Important Plants. Int. J. Life Sci. Biotechnol. 1:29-36.

Musayev, M. and Akparov, Z. 2013. Centuries-Old Results of Cultivation and Diversity of Genetic Resources of Grapes in Azerbaijan, in: The Mediterranean Genetic Code - Grapevine and Olive. https://doi.org/10.5772/52387

Myles, S., Boyko, A.R., Owens, C.L., Brown, P.J., Grassi, F., Aradhya, M.K., Prins, B., Reynolds, A., Chia, J.-M., Ware, D., Bustamante, C.D. and Buckler, E.S. 2011. Genetic structure and domestication history of the grape. Proc. Natl. Acad. Sci. U. S. A. https://doi.org/10.1073/pnas.1009363108

OIV. 2009. the OIV descriptor list for grape varieties and Vitis species., 2nd editio. ed. OIV International Organisation of Vine, Paris, France.

Portugal, Ç. 2010. Microsatellite database of grapevine (Vitis vinifera L.) cultivars used for wine production in Portugal. Ciência Téc. Vitiv 25:53-61.

Rohlf, F.J. 2000. NTSYS-pc Numerical Taxonomy and Multivariate Analysis System, version 2.1: Owner manual.

Rusjan, D. 2013. Genetic and Phenotypic Diversity and Relations Between Grapevine Varieties: Slovenian Germplasm. In: The Mediterranean Genetic Code - Grapevine and Olive. InTech, p. 13. https://doi.org/10.5772/51773

Sabir, A., Tangolar, S., Buyukalaca, S. and Kafkas, S. 2009. Ampelographic and molecular diversity among grapevine (Vitis spp.) cultivars. Czech J. Genet. Plant Breed. 45:160-168.

Santiago, J.L., Boso, S., Gago, P., Alonso-Villaverde, V. and Martínez, M.C. 2007. Molecular and ampelographic characterisation of Vitis vinifera L. "Albariño", "Savagnin Blanc" and "Caíño Blanco" shows that they are different cultivars. Spanish J. Agric. Res. 5:333-340.

Santiago, J.L., Boso, S., Martin, J.P., Ortiz, J.M. and Martinez, M.C. 2005. Characterization and identification of grapevine cultivars (Vitis vinifera L.) from northwestern Spain using microsatellite markers and ampelometric methods. Vitis 44:67-72. 
Sesli, M. and Yegenoglu, E.D. 2017. Genetic relationships in wild olives (Olea europaea ssp. oleaster) by ISSR and RAPD markers. Biotechnol. Biotechnol. Equip. 31:897-904.

Seyedimoradi, H., Talebi, R., Hassani, D. and Karami, F. 2012. Comparative genetic diversity analysis in Iranian local grapevine cultivars using ISSR and DAMD molecular markers 125-132.

Smith, B.P. 2010. Genetic and molecular mapping studies on a population derived from Vitis vinifera $\mathrm{x}$ Muscadinia rotundifolia and genetic diversity of wild Muscadinia rotundifolia. University of California, Davis.

Sneath, P.H.A. and Sokal, R.R. 1973. Numerical taxonomy. The principles and practice of numerical classification.

Soldavini, C., Schneider, A., Stefanini, M., Dallaserra, M. and Policarpo, M. 2009. Super ampelo, a software for ampelometric and ampelographic descriptions in vitis. Acta Hortic. 827:253-258.

Stavrakaki, M. and Biniari, K. 2017. Ampelographic and genetic characterization of grapevine varieties (Vitis vinifera L.) of the "Mavroudia" group cultivated in Greece. Not. Bot. Horti Agrobot. Cluj-Napoca 45:525-531.

Tassie, L. 2010. Vine identification - knowing what you have, The Grape and Wine Research and Development Corporation (GWRDC) Innovators network.

This, P., Lacombe, T. and Thomas, M.R. 2006. Historical origins and genetic diversity of wine grapes. Trends Genet. 22:511-519.

Tian, H.Z., Han, L.X., Zhang, J.L., Li, X.L., Kawahara, T., Yukawa, T., López-Pujol, J., Kumar, P., Chung, M.G. and Chung, M.Y. 2018. Genetic diversity in the endangered terrestrial orchid Cypripedium japonicum in East Asia: Insights into population history and implications for conservation. Sci. Rep. 8:1-13.

Williams, B.R. 2016. Investigation into the genetic basis of leaf shape morphology in Grapes. Missouri State University.

Zeinali, R., Rahmani, F., Abaspour, N. and Doulati, H. 2012. Molecular and morphological diversity among grapevine (Vitis vinifera L.) cultivars in Iran. Int. J. Agric. Res. Rev. 2: 735-743. 